\title{
Nocturnal enuresis: a placebo controlled trial of two antidepressant drugs
}

\author{
J M Smellie, V S McGrigor, S R Meadow, S J Rose, M F Douglas
}

\begin{abstract}
A multicentre, randomised, double blind treatment trial was set up comparing imipramine (a tricyclic antidepressant with anticholinergic action), mianserin (a quadricyclic antidepressant without anticholinergic activity), and placebo, (a) possibly to identify an effective alternative drug and (b) to elucidate the action of imipramine in enuretic children. Eighty children (65 boys, 15 girls) aged 5-13 years, wet three or more nights a week, were studied. Exclusions were a urinary tract infection or abnormality, other organic illness, or severe emotional disorders. After a four week assessment, 25 children were randomised to eight weeks' treatment with imipramine $25 \mathrm{mg}, 26$ to mianserin $10 \mathrm{mg}$ and 29 to placebo, followed by four weeks without treatment. Dry nights and a wetness score were recorded throughout.

During treatment, imipramine was superior to both placebo and mianserin $(p<0.001)$ in achieving dry nights and reducing wetness scores. It led to a definite improvement in $72 \%$ of children. Mianserin produced a mildly beneficial effect that was not superior to placebo. No side effects were recorded.

Mianserin would not be a satisfactory alternative treatment for nocturnal enuresis. The efficacy of imipramine is unlikely to be the result of its antidepressant activity.

(Arch Dis Child 1996;75:62-66)
\end{abstract}

Keywords: nocturnal enuresis, mianserin, imipramine.

Southampton and South West Hampshire Community Child Health Department J M Smellie

V S McGrigor

M F Douglas

St James's University Hospital, Leeds

S R Meadow

Royal Aberdeen Children's Hospital S J Rose

Correspondence to: Dr V S McGrigor, Central Health Clinic, East Park Terrace,

Southampton SO14 OYL.

Accepted 1 March 1996
Enuresis can be defined as the involuntary voiding of urine continuing after the anticipated age of control in the absence of an organic abnormality. An estimated $15 \%$ of 5 year old children suffer from nocturnal enuresis, more boys than girls, with an annual spontaneous cure rate of about $13 \% .{ }^{1}$ It causes distress to the child and to the family and can result in severe emotional disturbance and family discord. Many treatments have been used, the most effective currently being the bell and pad alarm system. ${ }^{2}$ Drugs have a limited role, but are useful to cover short periods when dryness is essential, such as school trips, camping holidays, or in children young or old who are almost ready to achieve spontaneous dryness.

Imipramine has been used effectively, ${ }^{34}$ although it may cause side effects when the dosage is increased and a relapse may follow cessation of treatment. It also carries a risk of accidental poisoning if swallowed by younger siblings, ${ }^{5}$ although this is now infrequent. The mechanism of action of imipramine is uncertain and has been attributed variously to a central antidepressant effect, or anticholinergic action, or to a direct effect on the bladder trigone. ${ }^{4}$

In view of the need for a safe and effective alternative to imipramine, an international multicentre, randomised, double blind therapeutic trial was set up involving centres in Finland, the Netherlands and Britain, comparing the effects of the tricyclic antidepressant imipramine, a quadricyclic antidepressant mianserin, and placebo. The dual objective was to search for a possible alternative drug treatment with a sustained response and to explore the mechanism of action of imipramine by comparing two effective antidepressant drugs, only one of which, imipramine, has additional anticholinergic activity. The results are presented in 80 children studied in the British centres: Southampton, Leeds, and Aberdeen.

\section{Methods}

The protocol of the study is outlined in fig 1 and was approved by each ethical committee.

\section{RECRUITMENT}

Children aged 5-13 years with nocturnal enuresis, bed wetting at least three nights a week, were recruited. (One child was included who had an earlier very wet record but who had an average of only 2.5 wet nights a week in the preceding four weeks.) The history was taken, a full clinical examination including height, weight, and blood pressure was carried out and a Rutter A questionnaire was completed to identify any severe emotional difficulties. Each urine sample was tested with a nitrite stick for bacteriuria, and for protein, sugar, bilirubin, and specific gravity and examined microscopically and cultured. Those with a history of uri-

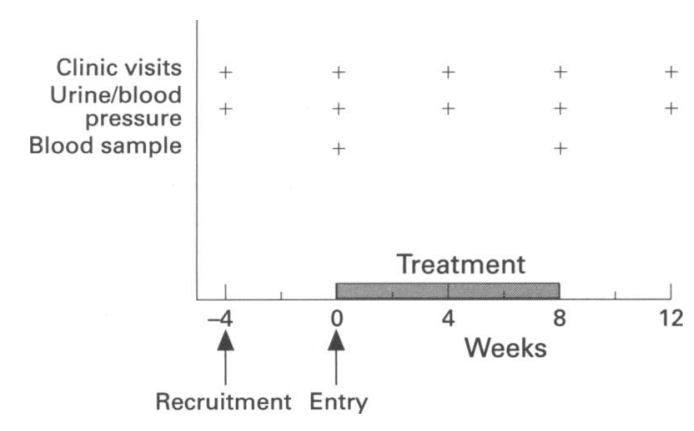

Figure 1 Protocol of study. 
nary tract infection or structural abnormality, secondary enuresis, moderate or severe learning difficulty, emotional or conduct disorder, anaemia, blood dyscrasia, epilepsy, neurological and endocrine disorders were excluded, as were any children with known drug allergies or receiving drugs which might interact with those under evaluation.

The children recruited had been referred to either a hospital or a community child health enuretic clinic by general practitioners, paediatricians, paediatric urologists or school doctors, all with their family doctors' knowledge and agreement.

The child was given a chart to record wet and dry nights over a four week period before specific treatment was prescribed.

ENTRY

After four weeks, the history, blood pressure and urine examination were repeated, and the record of wet and dry nights was checked. Children who satisfied the criteria and were sufficiently wet were entered, with written parental consent, to the randomised trial. A baseline blood sample was collected for electrolytes, liver and renal function, sugar, lipids, and full blood count. The children were supplied with charts on which, throughout the study, they recorded each dry night achieved and wet nights on a points system of 1 for moderate wetness and 2 for a 'soaking' night. They were also issued with a 30 days' supply of tablets identical in appearance and packaging containing either imipramine $25 \mathrm{mg}$, mianserin $10 \mathrm{mg}$ (doses with equivalent antidepressant activity), or placebo, to be taken each evening as a single dose. They were seen after four weeks and treatment was continued for a further four weeks. Unused tablets were returned and counted at the end of each four week period to check compliance. Tablets were prepared and supplied by Organon and the study was supervised and coordinated by $\mathbf{M r}$ Peter Wright. Randomisation was carried out centrally according to standard drug trial procedures and the key to randomisation was held by the local hospital pharmacist, in case of emergency.

After completion of eight weeks' treatment a blood sample was collected for a repeat blood screen. Follow up, with a performance record, was continued for a further four weeks without any tablets or other specific treatment. No change was made in the parents' current practice regarding fluid restriction or lifting.

Analysis of the results was carried out on the basis of (a) the number of dry nights achieved per week during each four week period, (b) the degree of wetness per week obtained by the mean of points scored, and (c) the number of children achieving seven or more consecutive dry nights.

\section{STATISTICAL METHOD}

Statistical analysis was performed using the SPSS package for the Kruskal-Wallis test and paired and non-paired Student's $t$ tests to compare means and also the $\chi^{2}$ test.
Table 1 Sex and age at entry of 80 children; figures indicate number (M:F)

\begin{tabular}{lcccl}
\hline \multicolumn{5}{c}{ Age (years) } \\
\cline { 2 - 5 } & $5<7$ & $7<10$ & $10<14$ & Total \\
\hline Imipramine & $9(7: 2)$ & $7(4: 3)$ & $9(8: 1)$ & $25(19: 6)$ \\
Mianserin & $7(5: 2)$ & $9(7: 2)$ & $10(10: 0)$ & $26(22: 4)$ \\
Placebo & $10(7: 3)$ & $12(11: 1)$ & $7(6: 1)$ & $29(24: 5)$ \\
Total & $26(19: 7)$ & $28(22: 6)$ & $26(24: 2)$ & $80(65: 15)$ \\
\hline
\end{tabular}

\section{Results}

Eighty children ( 65 boys, 15 girls) aged 5-13 years were entered to the study and randomisation is shown in table 1. Imipramine was prescribed in a dose of $25 \mathrm{mg}$ and mianserin $10 \mathrm{mg}$ each evening. The children who were consistently wet nearly every night (two or fewer dry nights per month) were overrepresented in the placebo group at entry (13 of 29, compared with nine of the 25 allocated to imipramine and nine of the 26 on mianserin); nevertheless, the median number of dry nights was one per week for each group (fig 2).

There was a family history of nocturnal enuresis in parents or siblings of 35 children, 10 of those randomised to imipramine, 11 to mianserin, and 14 to placebo.

All 80 children completed the preliminary four weeks' assessment and eight weeks' treatment, but no record was available for the final four weeks' observation without treatment in four children (two allocated to placebo, two to imipramine).

No physical or emotional side effects were reported and no biochemical or haematological changes or urinary infections occurred during the treatment period. Compliance was very good.

\section{DRY NIGHTS ACHIEVED}

The mean numbers of dry nights per child per week during the initial four week assessment period and subsequent four week periods on and after treatment are shown in fig 2 and expressed as a mean for each treatment group during each four week period of observation in fig 3. Both indicate that during imipramine treatment there was initial improvement which continued into the second treatment period (but was not well sustained when the drug was discontinued). In the mianserin and placebo groups, there appeared to be a steady, slower improvement which in some children only occurred between eight and 12 weeks, after stopping treatment.

Definite improvement was defined as an average increase of at least two dry nights per week. The results at the end of eight weeks' treatment are shown in table 2. Slight improvement was defined as an average increase of at least one dry night per week. This occurred during treatment in four of those receiving imipramine, five on mianserin, and six receiving placebo respectively.

There was a significant improvement in the number of dry nights during imipramine treatment compared with mianserin and with placebo $(\mathrm{p}<0.001)$ but there was no significant difference between the results of mian- 
Table 2 Definite improvement at the end of eight weeks' treatment

\begin{tabular}{llll}
\hline & \multicolumn{2}{l}{ Definite improvement } & \\
\cline { 2 - 4 } & No (\%) & Male $(n=65)$ & Female $(n=15)$ \\
\hline Imipramine $(\mathrm{n}=25)$ & $18(72)$ & 13 & 5 \\
Mianserin $(\mathrm{n}=26)$ & $10(38)$ & 10 & 2 \\
Placebo $(\mathrm{n}=29)$ & $11(38)$ & 9 & 7 \\
Total $(\mathrm{n}=80)$ & $39(49)$ & 32 & \\
\hline
\end{tabular}

Table 3 Slight or definite improvement at eight and 12 weeks

\begin{tabular}{|c|c|c|c|c|c|c|}
\hline & \multicolumn{3}{|c|}{ On treatment } & \multicolumn{3}{|c|}{ After treatment } \\
\hline & $\begin{array}{l}\text { No } \\
(n=80)\end{array}$ & $\begin{array}{l}\text { Improved } \\
\text { (\%) }\end{array}$ & $\begin{array}{l}\text { No } \\
\text { change }\end{array}$ & $\begin{array}{l}\text { No } \\
(n=76)\end{array}$ & $\begin{array}{l}\text { Improved } \\
(\%)\end{array}$ & $\begin{array}{l}\text { No } \\
\text { change }\end{array}$ \\
\hline Imipramine & 25 & $22(88)$ & 3 & 23 & $17(74)$ & 6 \\
\hline Mianserin & 26 & $15(58)$ & 11 & 26 & $14(54)$ & 12 \\
\hline Placebo & 29 & $17(59)$ & 12 & 27 & $16(59)$ & 11 \\
\hline
\end{tabular}

serin and placebo $(p=0.92)$. From start to end of treatment, while the increase in dry nights in the imipramine treated children was highly significant, there was also a significant improvement in the children receiving both mianserin and placebo (paired Student's $t$ test $\mathrm{p}<0.001$ for all three) (table 2).

\section{WET NIGHT SCORES}

Figure 4 indicates the effect of imipramine, mianserin, and placebo on the average weekly wetness scores for each group. Those receiving imipramine showed the lowest scores at the end of eight weeks of treatment and this was significantly superior to both mianserin ( $p=$ $0.002)$ and to placebo $(p=0.002)$. Overall there was a slower decline in wetness scores in the other two groups.

EFFECT OF STOPPING TREATMENT (8-12 WEEKS) (figs 2,3 , and 4 and table 3 )

After four weeks without treatment, some improvement was seen in $74 \%$ of those randomised to imipramine who completed the study, $54 \%$ and $59 \%$ respectively of those treated with mianserin and placebo. Definite improvement was maintained in $57 \%$ of those
Table 4 Thirty seven children achieving seven or more consecutive dry nights during and after treatment

\begin{tabular}{lllll}
\hline & \multicolumn{3}{c}{ Consecutive dry nights } & \\
\cline { 2 - 4 } & $7<14$ & $14<21$ & $21+$ & Total \\
\hline Imipramine $(\mathrm{n}=25)$ & 10 & 5 & 6 & 21 \\
Mianserin $(\mathrm{n}=26)$ & 6 & 1 & 2 & 9 \\
Placebo $(\mathrm{n}=29)$ & 3 & 2 & 2 & 7 \\
Total $(\mathrm{n}=80)$ & 19 & 8 & 10 & 37 \\
\hline
\end{tabular}

who received imipramine, $38 \%$ and $37 \%$ of the other two groups. Some relapse occurred on cessation of tablets in 18 children who had improved during treatment: in 11 who received imipramine, three mianserin, and four who received placebo.

\section{CONSECUTIVE DRY NIGHTS}

At entry, the maximum number of consecutive dry nights recorded was three in 20 children, four in four children, and 5-8 consecutive dry nights in three children, all evenly distributed through the treatment groups.

During the whole period of study, 37 children achieved at least one sequence of seven or more consecutive dry nights as shown in table 4 . The longest periods recorded, were $36,28,25$, and 24 days (imipramine); 25,24 , and 17 days (mianserin); and 70, 32, and 20 days (placebo). (One child who was initially wet every night became dry after two weeks on placebo.) There was a significant difference between the effect of imipramine and mianserin $\left(\chi^{2}=10.88, p=0.001\right)$ and of imipramine and placebo $\left(\chi^{2}=16.94, \mathrm{p}<0.001\right)$ in this respect, but not between mianserin and placebo $(p=0.57)$.

\section{AGE, SEX, FAMILY HISTORY, AND DEGREE OF} WETTING

After eight weeks of treatment, there had been definite improvement in $39(49 \%)$ of the 80 studied, $49 \%$ of the boys and $47 \%$ of the girls (table 2). Two thirds of the improvement occurred in the children under 7 years of age,

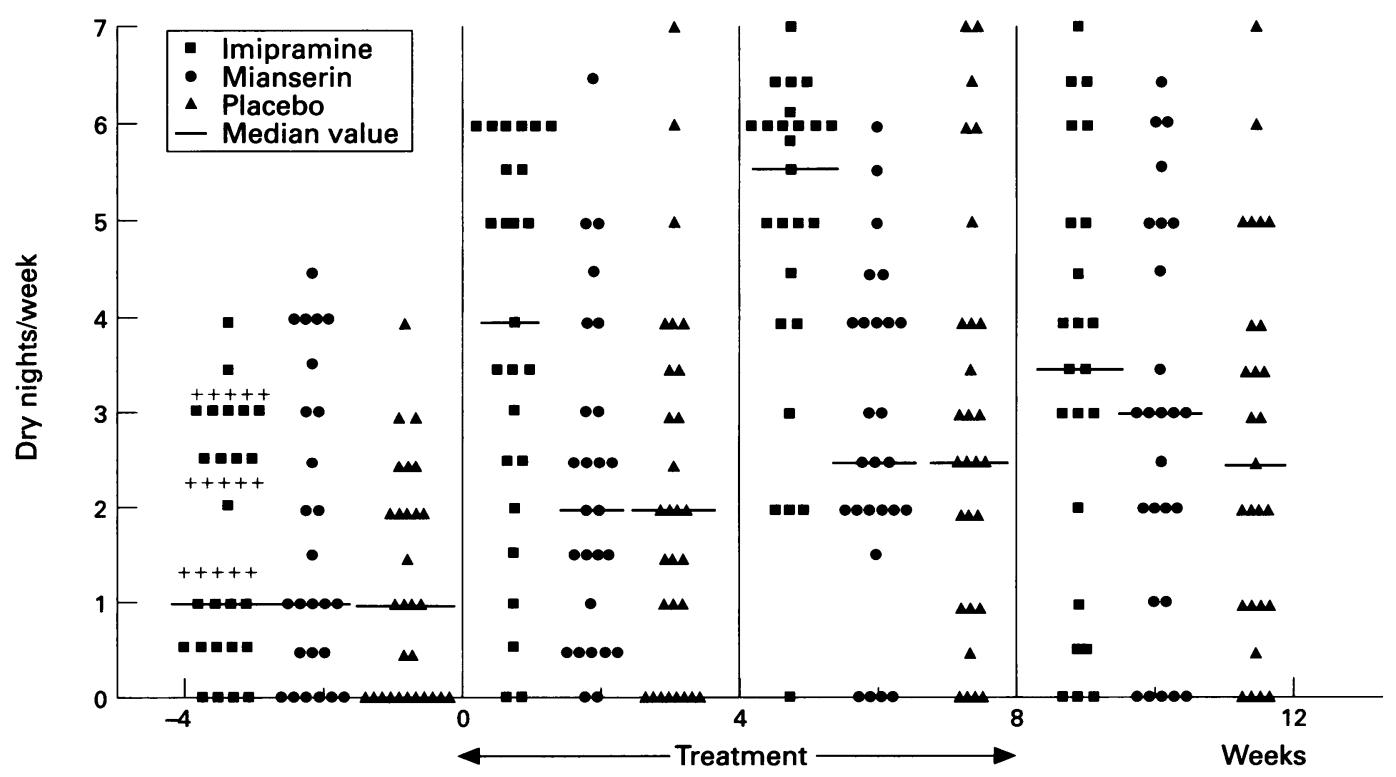

Figure 2 Mean number of dry nights per week in individual children. 
but there were no significant differences in either the sex or age distribution of response to treatment overall between the groups. Family history did not influence the results.

\section{SEVERE ENURETICS}

Thirty one children, 26 of whom were boys, were dry only 0-2 nights in the four weeks before treatment. Eight of the nine treated with imipramine improved (although three of these relapsed to almost complete wetness after stopping treatment), whereas five of the nine receiving mianserin and seven of the 13 on placebo (one becoming dry within two weeks) showed some improvement.

\section{Discussion}

Despite the widespread use of drugs in the treatment of nocturnal enuresis, there have been few reports of placebo controlled trials. The efficacy of imipramine in children has long been established ${ }^{46}$ and this has been confirmed in the randomised double blind trial reported here. In 80 children with nocturnal enuresis, imipramine was significantly more effective than placebo and mianserin in improving the bed wetting problem, both in terms of dry nights achieved, in series of consecutive dry nights, and in reducing the degree of wetness during treatment. There was no significant difference between the effect of mianserin and placebo. Some relapse after stopping treatment was seen in children in all three groups.

These results indicate that the quadricyclic antidepressant mianserin would not be suitable for the treatment of children with nocturnal enuresis. The steady improvement seen during treatment with both mianserin and placebo does, however, emphasise the importance of

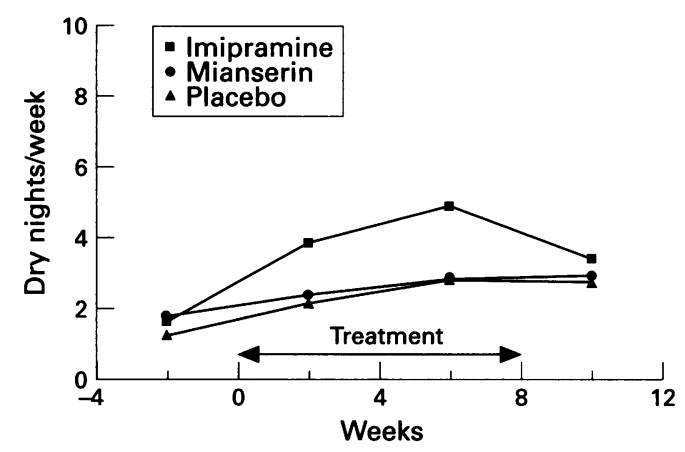

Figure 3 Mean number of dry nights during four week periods.

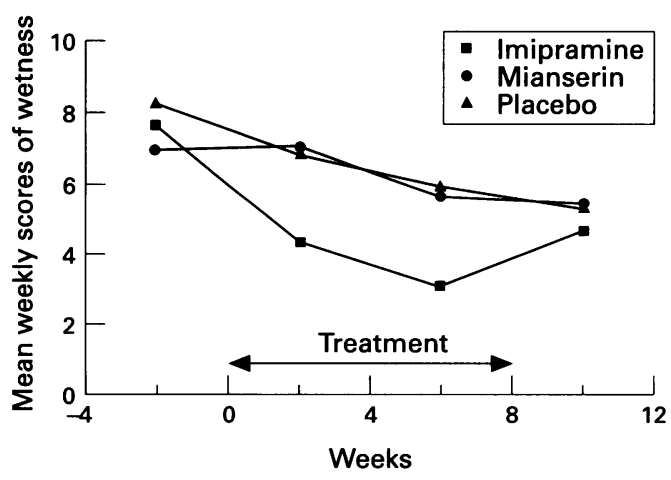

Figure 4 Mean wetness scores during four week periods. regular supervision and encouragement. The planned study was not continued beyond the 12 week period, but most of those under continued supervision rapidly became dry with the enuretic alarm system.

The clearest difference between imipramine and the other treatments was in the unbroken sequences of seven or more dry nights. These were of longer duration and occurred in a higher proportion of children treated with imipramine than in the other two groups, both during and after treatment. However, only two children remained consistently dry for more than four weeks, one who received imipramine and one placebo.

The precise mechanism of action of imipramine in children with nocturnal enuresis remains unclear. The results of this study suggest that its efficacy is not due to its antidepressant activity, although other tricyclic antidepressant drugs with anticholinergic activity such as amitriptyline have proved similarly effective. ${ }^{7}$ However the anticholinergic drug propantheline is not effective. ${ }^{8}$ It is therefore unlikely that the beneficial effect of the tricyclic antidepressants results from their anticholinergic activity. Possible alternative mechanisms include a direct nor-adrenergic effect on the bladder trigone or a central effect other than antidepression.

Drugs are of limited value in the treatment of enuresis because those of proved value (tricyclic antidepressants and desmopressin) help in only half the children treated and relapse after cessation of treatment is usual. ${ }^{3} 7910$ They may have undesirable side effects, particularly if treatment is prolonged or dosage high. ${ }^{4}$ There is also a risk of poisoning of younger siblings, though this has become less common with greater awareness of the problem, caution in prescribing, and warning of parents. Although drugs for the treatment of enuresis are widely used, they are neither licensed nor advised for children under the age of 5 years and preferably should not be used until the age of 7 . For these various reasons the indications for their use in enuretics are mainly limited to coverage of school visits, holidays, and perhaps enthusiastic older children who are ready to become dry.

\section{Conclusion}

Imipramine was shown in this study to be effective in improving nocturnal enuresis during treatment, although often followed by relapse and was significantly superior to mianserin and placebo. The mechanism of action of imipramine remains unclear, but does not appear to be due to its antidepressant effect.

Regular supervision and encouragement without effective drug treatment can produce a significant increase in dry nights.

We are grateful to Mrs Margaret Hicks and Sister June Wilson and their staff and the staff of the Royal Aberdeen Children's Outpatient Clinic, to Organon for supplying the drug preparations, and Mr Peter Wright for facilitating the study, to Mrs Jan Port for secretarial help, and particularly to the children and their parents for their cooperation and faithful clinic attendance.

1 Forsythe WI, Redmond A. Enuresis and spontaneous cure rate: study of 1129 enuretics. Arch Dis Child 1974; 49: 259- 
2 Alon US. Nocturnal enuresis. Pediatr Nephrol 1995; 9: 94-103.

3 Shaffer D, Costello AJ, Hill ID. Control of enuresis with imipramine. Arch Dis Child 1968; 43: 665-71.

4 Blackwell B, Currah J. The psychopharmacology of nocturnal enuresis. In: Kolvin I, MacKeith RC, Meadow SR, eds. Bladder control and enuresis. London:Heinemann, 1973 231-57.

5 Goel KM, Shanks RA. Amitriptyline and imipramine poisoning in children. $B M \mathcal{F} 1974$; i: $261-3$.

6 Rushden HG. Nocturnal enuresis: epidemiology, evaluation and currently available treatment options. $\mathcal{F}$ Pediatr 1989 114: 691-6.
7 Burke JR, Mizusawa Y, Chan A, Webb KL. A comparison of amitriptyline, vasopressin and amitriptyline with vasopressin in nocturnal enuresis. Pediatr Nephrol 1995; 438-40. Wallace IR, Forsythe WI. The treatment of enuresis: a controlled clinical trial of propantheline, propantheline-andphenobarbitone and a placebo. Br f Clin Pract 1969; 23: 207-9.

9 Evans JHC, Meadow SR. Desmopressin for bedwetting: length of treatment, vasopressin secretion and response. Arch Dis Child 1992; 67: 184-8.

10 Moffatt MEK, Harlos S, Kirschen AJ, Bird L. Desmopressin acetate and nocturnal enuresis, how much do we know? Pediatrics 1993; 92: 420-5. 